\title{
Relationships between Vitamin B12, Folate Levels and Clinical Features in Attention Deficit Hyperactivity Disorder and Attention Deficit Hyperactivity Disorder-Not Otherwise Specified
}

\author{
(1) Yusuf Öztürk1, (1) Zehra Topal2, (1) Nuran Demir33, @ Ali Evren Tufan4 \\ 1Bolu Abant Izzet Baysal University Faculty of Medicine, Department of Child and Adolescent Psychiatry, Bolu, Turkey \\ ${ }^{2}$ Gaziantep University Faculty of Medicine, Department of Child and Adolescent Psychiatry, Gaziantep, Turkey \\ ${ }^{3}$ Yıldırım Beyazıt University, Yenimahalle Training and Research Hospital, Clinic of Child and Adolescent Psychiatry, Ankara, Turkey \\ ${ }^{4}$ Acıbadem University Faculty of Medicine, Department of Child and Adolescent Psychiatry, İstanbul, Turkey
}

\begin{abstract}
Aim: In this study, we aimed to compare the levels of vitamin B12 and folate in children with Attention Deficit and Hyperactivity Disorder (ADHD) and Attention Deficit and Hyperactivity Disorder-Not Otherwise Specified (ADHD-NOS).

Materials and Methods: This study was planned as a cross-sectional, retrospective study. Patients were recruited between January 2012 and lanuary 2013 and 205 case records were evaluated. The ADHD and ADHA-NOS groups were compared according to vitamin B12 and folate levels. Symptom severity was evaluated by the Turgay DSM-IV-Based Child and Adolescent Behavior Disorders Screening and Rating scale. Anxiety symptom severity was assessed by The Screen for Anxiety Related Emotional Disorders.

Results: The average age of the children in the ADHD group was $10.88 \pm 3.02(n=99)$ years, and the average age of the children in the ADHD-NOS group was $9.93 \pm 2.49$ ( $n=106$ ) years. There was no statistically significant difference between two groups in terms of Vitamin B12 level and folate level $(p>0.05)$. A statistically significant negative correlation between the total number of diagnoses of a child and vitamin B12 levels was found. Folate levels correlated significantly with anxiety total scores generalized anxiety subscale.

Conclusion: Vitamin B12 levels may be affected in children with impairing ADHD symptoms and increased comorbidities. The results of the study should be supported by future studies.

Keywords: ADHD, vitamin B12, folate
\end{abstract}

\section{Introduction}

Attention Deficit Hyperactivity Disorder (ADHD) is a neurodevelopmental disorder having different clinical symptoms including inattention, hyperactivity, and impulsivity. It is also frequently related to cognitive deficit (1). It has been reported that the prevalence of ADHD ranges between $8.0-12.0 \%$ worldwide (2). The prevalence of ADHD was found to be $8.1 \%$ in school-age children in Turkey (3). Attention Deficit Hyperactivity Disorder-Not
Otherwise Specified (ADHD-NOS) was defined for disorders with inattention/ hyperactivity-impulsivity that do not fully meet the criteria for ADHD in Diagnostic and Statistical Manual of Mental Disorders, $4^{\text {th }}$ Edition, Text Revision (DSMIV-TR) (4). It was replaced with ADHD- Unspecified in DSM-5 (1) and seems to be used as a diagnosis for conditions where children have moderate attention problems in school, which can be better characterized as difficulties in children's learning or executive function (4). In addition, rather than being categorized as ADHD Other Specified and Unspecified 
types, many young people are defined as having borderline or subclinical levels of ADHD instead. Pharmacotherapy including stimulants and atomoxetine is the first choice in the treatment of both disorders (2).

The etiology of ADHD is complex and has not yet been identified. There is no specific definable factor, ADHD is multi-component (5). Its heritability was found to differ between $76.0 \%$ and $80.0 \%$. Thus, it is one of the highest hereditary neuropsychiatric disorders $(6,7)$. Although the exact reason is not known, exposure to heavy metals and toxins in the prenatal and perinatal period, sociopsychological stress, diet, gene variants and abnormalities of the brain, neurotransmitter deficiency and dysfunction in the frontostriatal, as well as fronto-cerebellar catecholaminergic circuits, were reported to contribute to the etiology $(2,6,8)$.

Psychiatric symptoms related to vitamin B12 and folate deficiencies may consist of irritability, agitation, negativism, disorientation, confusion, amnesia, problems of concentration and attention and insomnia. It is considered that vitamin B12 and folate in the carbon transfer metabolism (i.e. methylation) play a significant role in psychiatric symptoms. They are also essential in the production of dopamine, serotonin, other monoamine neurotransmitters and catecholamines (9). Basal ganglia, which is considered to play a significant role in ADHD, may be especially vulnerable to deficiencies of vitamin B12 and folate. Studies on the relationship of ADHD with folate and related metabolic pathways have focused on the consequences of folate deficiency in the prenatal period (10). A recent study from Turkey also reported that ADHD may be related to methylene tetrahydrofolate reductase polymorphisms (11).

The lack of vitamin B12 and folate levels in the diet were associated with ADHD (12). It was reported that there is a relationship between maternal folate deficiency during early pregnancy and childhood hyperactivity (10). The serum levels of vitamin B12 were conversely related to depression in some studies (13-15) but not in others $(16,17)$. Although major depressive disorder and anxiety disorder are common comorbid diseases, the effect of serum vitamin B12 and folate levels in anxiety has been investigated in few studies.

We aimed to compare the levels of vitamin B12 and folate in children with ADHD and ADHD-NOS in this study. We also aimed to assess the relationship between ADHD symptom severity, and anxiety symptom severity with vitamin B12 and folate levels.

\section{Materials and Methods}

\section{Study Center and Time-frame}

This study was planned as a cross-sectional, retrospective study. It was conducted at the outpatient department of Child and Adolescent Psychiatry in Abant Izzet Baysal University Faculty of Medicine. Patients were recruited between January 2012 and January 2013 and 205 case records were evaluated. The diagnoses of 205 patients' records and their comorbid psychiatric disorders were made clinically by the consensus of child psychiatry residents and the clinical supervisor according to DSM-IV-TR criteria (4).

Inclusion criteria were a primary diagnosis of ADHD or ADHD-NOS according to DSM-IV-TR criteria, adequate information on laboratory values and psychometric measures in patient records, and application to the outpatient department between the specified time-frame. Patients with comorbid medical and psychiatric disorders were included. Both ADHD and ADHD-NOS groups received methylphenidate treatment at $1 \mathrm{mg} / \mathrm{kg} /$ day. Patients with inadequate records were excluded.

The Ethics Committee approval of the study was obtained from Bolu Abant İzet Baysal University Clinical Trials Ethics Committee (date: 16.05.2018, number: 164).

\section{Measures}

Turgay DSM-IV-Based Child and Adolescent Behavior Disorders Screening and Rating scale: This scale was developed by Turgay by transforming the DSM-IV criteria (T-DSM-IV-S) into questions without changing their meanings. It includes 41items (attention deficit $=9$ items, hyperactivity $=6$ items, impulsivity $=3$ items, oppositional defiant disorder $=8$ items, and conduct disorder $=15$ items). Each item is rated on a scale of $0=$ none, $1=$ occasional, $2=$ much, and 3 = very much. When subscales are evaluated, 2 to 3 points per item are assessed as symptomatic (1), while 0 to 1 are assessed as not symptomatic (0) (18). The validity and reliability study of this scale was established previously (19).

The Screen for Anxiety Related Emotional Disorders (SCARED): There are 41 items to determine anxiety symptom severity in the previous three months in this scale. Participants may choose a score between 0 (not true or hardly ever true) and 2 (very true or often true) (20). When the subscales are evaluated, 2 points per item is assessed as symptomatic (1), while 0 to 1 are assessed as not symptomatic (0). It was used according to both the child and their parent's report. The scale also includes generalized anxiety, somatic/panic, social anxiety, separation anxiety 
and school fear subscales. The validity and reliability for the SCARED Turkish form was established by Cakmakci (21).

The Clinical Global Impression-severity scale (CGIS): CGI-S is a clinician-rated measure which is used for treatment-related changes in functioning (22). The CGI-S score varies between 1 (normal) and 7 (most severely patients). CGI-S is mostly used in Turkish Child and Adolescent Psychiatry outpatient clinics. There are many Turkish clinical studies which have used this scale. CGI-S was used to indicate symptom severity in the present study.

\section{Statistical Analysis}

Statistical analysis of the data for this study was carried out using the Statistical Package for the Social Sciences (SPSS 22.0) software. Number values and percentages were used in the evaluation of some study and control group socio-demographic and clinical categorical variables. Continuous variables are presented using summary statistics. This (unless otherwise stated) refers to the number of patients ( $n)$, mean and standard deviation. Categorical data are presented using either absolute or relative frequencies. Yates' and Fisher's corrections were applied when required. The Kolmogorov-Smirnov method was used for the evaluation of data distribution. As the data distribution was found to be normal, the Parametric t-test or one-way ANOVA, depending on group numbers, was used to evaluate paired groups. Pearson correlation analysis was used to determine the relationship between continuous variables. All tests were two-tailed with $p$ values $<0.05$ considered significant.

\section{Results}

The records of 205 patients were analyzed. Of these, 99 (48.29\%) patients were ADHD and 106 (51.71\%) patients were ADHD-NOS. Comparison of sociodemographic data of the ADHD-NOS and ADHD groups is shown in Table I. T- DSM-IV-S-parent subscales, SCARED subscales and CGI-S scores between the two groups are presented in Table II.

Comorbid psychiatric disorder was detected in 144 cases (70.24\%) of the 205 cases included in the study. It was found that conduct disorder (28.29\%) and specific learning difficulties $(21.95 \%)$ were the most common comorbid psychiatric disorders. While 71 of these 144 cases had one comorbid psychiatric disorder, others had multiple comorbid psychiatric disorders. It was found that 76 cases in the ADHD group and 68 cases in the ADHD-NOS group had comorbid psychiatric disorders. No statistically significant difference was found between the two groups in terms of comorbid psychiatric disorders $(p=0.531)$.
Vitamin B12 levels were measured in 89 of 205 patients participating in the study. Folate levels were measured in 82 of 205 patients participating in the study. There was no

Table I. Comparison of sociodemographic data of the attention deficit and hyperactivity disorder and attention deficit and hyperactivity disorder-not otherwise specified groups

\begin{tabular}{|c|c|c|c|}
\hline & $\begin{array}{l}\text { ADHD-NOS group } \\
(n=99)\end{array}$ & $\begin{array}{l}\text { ADHD group } \\
(n=106)\end{array}$ & $\mathbf{p}$ \\
\hline Age & $10.88 \pm 3.02$ & $9.93 \pm 2.49$ & 0.015 \\
\hline \multicolumn{4}{|l|}{ Gender } \\
\hline Male & 65 & 72 & \multirow{2}{*}{0.73} \\
\hline Female & 34 & 34 & \\
\hline \multicolumn{4}{|c|}{ Family history } \\
\hline Positive & 54 & 45 & 0.095 \\
\hline Negative & 45 & 61 & \\
\hline \multicolumn{4}{|c|}{ Medical disease history } \\
\hline Positive & 48 & 51 & 0.958 \\
\hline Negative & 51 & 55 & \\
\hline
\end{tabular}

Table II. Comparison of T-DSM-IV-S-parent subscales, screen for anxiety related emotional disorders subscales and clinical global impression-severity scale scores of the attention deficit and hyperactivity disorder-not otherwise specified and attention deficit and hyperactivity disorder groups

\begin{tabular}{|c|c|c|c|}
\hline & $\begin{array}{l}\text { ADHD-NOS } \\
\text { group } \\
(n=99)\end{array}$ & $\begin{array}{l}\text { ADHD } \\
\text { group } \\
(n=106)\end{array}$ & $\mathrm{p}$ \\
\hline \multicolumn{4}{|l|}{ T-DSM-IV-S-parent } \\
\hline Attention & $2.41 \pm 1.72$ & $6.28 \pm 2.15$ & $<0.001$ \\
\hline Hyperactivity & $1.40 \pm 1.85$ & $4.52 \pm 3.18$ & $<0.001$ \\
\hline Opposition-defiance & $1.45 \pm 2.02$ & $3.56 \pm 2.99$ & $<0.001$ \\
\hline$C D$ & $0.11 \pm 0.46$ & $0.56 \pm 1.22$ & 0.001 \\
\hline Total score & $21.34 \pm 11.41$ & $42.37 \pm 17.02$ & $<0.001$ \\
\hline \multicolumn{4}{|l|}{ SCARED } \\
\hline Somatic/panic & $1.85 \pm 2.31$ & $2.29 \pm 2.47$ & 0.441 \\
\hline Generalized anxiety & $1.32 \pm 1.98$ & $3.11 \pm 2.64$ & 0.001 \\
\hline Separation anxiety & $1.43 \pm 1.68$ & $2.68 \pm 1.92$ & 0.003 \\
\hline Social anxiety & $2.09 \pm 1.95$ & $2.85 \pm 2.22$ & 0.106 \\
\hline School phobia & $0.53 \pm 1.31$ & $1.15 \pm .142$ & 0.050 \\
\hline Total score & $25.89 \pm 12.86$ & $34.00 \pm 12.89$ & 0.007 \\
\hline CGI-S & $3.39 \pm 0.74$ & $4.55 \pm 0.64$ & $<0.001$ \\
\hline \multicolumn{4}{|c|}{$\begin{array}{l}\text { ADHD: Attention deficit and hyperactivity disorder, ADHD-NOS: Attention } \\
\text { deficit and hyperactivity disorder-not otherwise specified, n: Number of } \\
\text { patients, SCARED: Screen for anxiety related emotional disorders, CGI-S: } \\
\text { Clinical global impression-severity scale }\end{array}$} \\
\hline
\end{tabular}


statistically significant difference between the groups in terms of Vitamin B12 and folate levels ( $p=0.989, p=0.855$; respectively) (Table III).

When the relationship between B12 vitamin levels and comorbidity was evaluated, vitamin B12 levels were $355.02 \pm 157.32$ in the non-comorbid group, $342.14 \pm 159.25$ in the single comorbid group and, 294.22 \pm 120.38 in the multiple comorbid group. No statistically significant difference was determined between the three groups in terms of vitamin B12 levels ( $p=0.218)$. When the relationship between folate levels and comorbidity was evaluated, folate levels were $9.14 \pm 2.09$ in the non-comorbid group, $7.91 \pm 2.38$ in the single comorbid group and, $8.63 \pm 2.82$ in the multiple comorbid group. There was no statistically significant difference between the three groups in terms of folate levels $(p=0.217)$. When the relationship between the total number of diagnosis and vitamin B12, folate was assessed, a statistically significant negative correlation was found between the total number of diagnoses and vitamin B12 levels $(r=-0.214, p=0.044)$, but the same relationship with folate levels was not obtained ( $p>0.05$ ).

When the relationship between the symptoms of ADHD and vitamin B12 and folate was evaluated, no relationship was found between the symptoms of ADHD and either Vitamin B12 or folate (Table IV). However, when the relationship between SCARED scores and vitamin B12 and

Table III. Comparison of vitamin B12 and folate levels of the attention deficit and hyperactivity disorder-not otherwise specified and attention deficit and hyperactivity disorder groups

\begin{tabular}{|l|l|l|l|}
\hline & $\begin{array}{l}\text { ADHD-NOS } \\
\text { group }\end{array}$ & $\begin{array}{l}\text { ADHD } \\
\text { group }\end{array}$ & p \\
\hline $\begin{array}{l}\text { Vitamin B12, pg/mL } \\
\text { (rr: } 187-883 \mathrm{pg} / \mathrm{mL})\end{array}$ & $328.28 \pm 126.97$ & $327.84 \pm 159.61$ & 0.989 \\
\hline $\begin{array}{l}\text { Folate, } \mathrm{ng} / \mathrm{mL} \\
\text { (rr: } 3.1-20.5 \mathrm{ng} / \mathrm{mL})\end{array}$ & $8.64 \pm 2.56$ & $8.54 \pm 2.46$ & 0.855 \\
\hline \multicolumn{3}{|l|}{ rr: Reference range, ADHD: Attention deficit and hyperactivity disorder, ADHD- } \\
NOS: Attention deficit and hyperactivity disorder-not otherwise specified
\end{tabular}

Table IV. Examination of the relationship between attention deficit and hyperactivity disorder symptoms and vitamin B12 and folate levels (Pearson correlation analysis)

\begin{tabular}{|c|c|c|c|}
\hline & & Vitamin B12 level & Folate level \\
\hline \multicolumn{4}{|c|}{ T-DSM-IV-S-parent } \\
\hline Attention & $\begin{array}{l}r \\
p\end{array}$ & $\begin{array}{l}-0.159 \\
0.169\end{array}$ & $\begin{array}{l}-0.157 \\
0.192\end{array}$ \\
\hline Hyperactivity & $\begin{array}{l}r \\
p\end{array}$ & $\begin{array}{l}-0.092 \\
0.428\end{array}$ & $\begin{array}{l}-0.043 \\
0.721\end{array}$ \\
\hline Total score & $\begin{array}{l}r \\
p\end{array}$ & $\begin{array}{l}-0.128 \\
0.271\end{array}$ & $\begin{array}{l}0.016 \\
0.898\end{array}$ \\
\hline
\end{tabular}

folate levels was evaluated, while no relationship was found between B12 levels and SCARED subscales and total scores $(p>0.05)$, a significant relationship was found between folate and SCARED total score and the generalized anxiety disorder (GAD) subscale (respectively $p=0.050, p=0.039$ ) (Table V).

Table V. Examination of the relationship between screen for anxiety related emotional disorders subscales and total score and Vitamin B12 and folate levels (pearson correlation analysis)

\begin{tabular}{|c|c|c|c|}
\hline & & $\begin{array}{l}\text { Vitamin B12 } \\
\text { level }\end{array}$ & $\begin{array}{l}\text { Folate } \\
\text { level }\end{array}$ \\
\hline \multicolumn{4}{|l|}{ SCARED } \\
\hline Somatic/panic & $\begin{array}{l}r \\
p\end{array}$ & $\begin{array}{l}0.151 \\
0.346\end{array}$ & $\begin{array}{l}0.091 \\
0.596\end{array}$ \\
\hline Generalized anxiety & $\begin{array}{l}r \\
p\end{array}$ & $\begin{array}{l}0.227 \\
0.154\end{array}$ & $\begin{array}{l}0.345 \\
0.039\end{array}$ \\
\hline Separation anxiety & $\begin{array}{l}r \\
p\end{array}$ & $\begin{array}{l}0.163 \\
0.309 \\
\end{array}$ & $\begin{array}{l}0.320 \\
0.057\end{array}$ \\
\hline Social anxiety & $\begin{array}{l}r \\
p\end{array}$ & $\begin{array}{l}0.162 \\
0.311\end{array}$ & $\begin{array}{l}0.322 \\
0.055 \\
\end{array}$ \\
\hline School phobia & r & $\begin{array}{l}0.223 \\
0.172\end{array}$ & $\begin{array}{l}0.194 \\
0.265\end{array}$ \\
\hline Total score & r & $\begin{array}{l}0.146 \\
0.364\end{array}$ & $\begin{array}{l}0.329 \\
0.050\end{array}$ \\
\hline
\end{tabular}

\section{Discussion}

In this retrospective study, we aimed to compare the levels of vitamin B12 and folate in children with ADHD and ADHD-NOS, and to assess the relationship between ADHD symptom severity and anxiety symptom severity with vitamin B12 and folate levels. While we did not find a significant difference between ADHD and ADHD-NOS groups in terms of Vitamin B12 and folate levels, we found a statistically significant negative correlation between the total number of diagnoses and vitamin B12 levels. We also found a significant correlation between folate levels and the SCARED total score and GAD subscale.

The main outcome of this study is a significant negative correlation between the total number of psychiatric disorder diagnoses with ADHD and ADHD-NOS and vitamin B12 levels. This means that as the vitamin B12 level decreases, the number of psychiatric diagnoses increases. Vitamin B12 deficiency affects many systems. It has been shown to cause megaloblastic anemia, glossitis, atrophic gastritis, neuropathy, and demyelination in the nervous system $(23,24)$. Moreover, previous studies have demonstrated the association of deficiency in vitamin 
B12 with numerous neurological and psychiatric disorders $(25,26)$. The association between vitamin B12 deficiency and neurodevelopment was reported in observational studies in children (27-29). In North Indian children, it was found that their vitamin B12 level was related to lower scores on the mental development scale in a study (28). Ssonko et al. (30) found that low serum vitamin B12 was common among inpatient psychiatric patients. They also suggested routine screening of serum vitamin B12 for hospitalized psychiatric patients. Both the previous results and our findings suggest a probable relationship between vitamin B12 deficiency and psychopathology, including neurodevelopmental disorders such as ADHD.

We also observed a significant correlation between folate levels and the SCARED total score and GAD subscale. This means that as folate levels increase, anxiety symptom severity increases. Folate is a fundamental nutrient. It regulates apoptosis, neural stem cell proliferation and differentiation, various biochemical pathways such as DNA biosynthesis, neurotransmitter and myelin synthesis, regulation of gene expression, amino-acid synthesis and metabolism (31,32). In a meta-analysis study, it was suggested that low folate levels may be associated with depression (33). In previous studies, there were few studies examining the effect of serum vitamin B12 and folate levels in anxiety $(34,35)$. Møllehave et al. (34) found no association between serum vitamin B12 and folate levels with depression and anxiety symptoms. In another study, it was found that while plasma folate level was related to depression, it was not related to anxiety (35). Although we found an association between folate levels and anxiety symptoms, there is a need for further study in this area because the number of samples and the information in the literature are inadequate.

Another finding we have in our study is that there is no significant difference between ADHD and ADHD-NOS groups concerning vitamin B12 and folate levels. Our study may be a contribution to the literature on this subject. There is no study in the literature assessing the association between ADHD and ADHD-NOS in terms of vitamin B12 and folate levels. In previous studies, ADHD was compared with autism spectrum disorder (ASD) and healthy controls with regard to vitamin B12 and folate levels $(36,37)$. Bala et al. (36) compared vitamin and hormones levels in ADHD, ASD and healthy control groups. They found that the vitamin B12 level in the ADHD group was 371.72 \pm 160.63 [minimum $(\min )=156 /$ maximum $(\max )=924]$, and the folate level in the ADHD group was $10.16 \pm 2.93$ ( $\min =4 / \max =15$ ). They also found the lowest vitamin B12 level in the ASD group and statistically significant differences between the three groups. However, there was no difference in folate levels between the three groups. More studies are needed to evaluate the association of ADHD with vitamin B12 and folate levels.

\section{Study Limitations}

Our findings should be evaluated within the context of certain limitations. Firstly, this study was retrospective and depended on information recorded routinely in clinical records. This dependence led to missing data which may have affected our results. Secondly, this study was conducted on a clinical sample evaluated at a single center and may not reflect patient populations in other centers or the community. Thirdly, the laboratory evaluations were conducted as part of the baseline examination prior to commencing pharmacotherapy at the study center. However, due to a dependence on patient charts, we could not ascertain whether the patients were drug naive or were receiving treatment at the time of their evaluations. Despite these limitations, this is the only study that we are aware of evaluating the psychometric features and laboratory values of children diagnosed with ADHD and ADHD-NOS.

\section{Conclusion}

In conclusion, it has been shown in our study that there a negative relationship between the number of psychiatric diagnoses and vitamin B12 levels for ADHD patients. This finding suggests that assessing vitamin B12 levels in children with ADHD may be beneficial if the number of psychiatric diagnoses is high. We have also shown a positive relationship between folate levels and anxiety symptom severity. However, there is a need for further study in this area because our findings and literature information are inadequate to generalize our findings.

\section{Ethics}

Ethics Committee Approval: The Ethics Committee approval of the study was obtained from Bolu Abant İzet Baysal University Clinical Trials Ethics Committee (date: 16.05.2018, number: 164).

Informed Consent: Retrospective study.

Peer-review: Enternally peer-reviewed.

\section{Authorship Contributions}

Surgical and Medical Practices: Z.T., N.D., Concept: Y.Ö., Design: Y.Ö., Z.T., Data Collection or Processing: Z.T., Y.Ö., N.D., Analysis or Interpretation: A.E.T., Literature Search: A.E.T., Writing: Y.Ö., Z.T., N.D. 
Conflict of Interest: None of the authors had conflict of interest.

Financial Disclosure: The authors declared that this study received no financial support.

\section{References}

1. American Psychiatric Association. 'Diagnostic and statistical manual of mental disorders. 5th ed. Text Revision' 2013. Washington, DC: American Psychiatric Association Pres.

2. Biederman J, Faraone SV. Attention deficit hyperactivity disorder. Lancet 2005; 66:237-48.

3. Erşan EE, Doğan $O$, Doğan $S$, Sümer $H$. The distribution of symptoms of attention-deficit/hyperactivity disorder and oppositional defiant disorder in school age children in Turkey. Eur Child Adolesc Psychiatry 2004; 13:354-61.

4. American Psychiatric Association. 'Diagnostic and statistical manual of mental disorders. 4th ed. Text Revision' 2000. Washington, DC: American Psychiatric Association Pres.

5. Biederman J. Attention-deficit/hyperactivity disorder: a selective overview. Biol Psychiatry 2005; 57:1215-20.

6. Faraone SV, Perlis RH, Doyle AE, et al. Molecular genetics of attention-deficit/hyperactivity disorder. Biol Psychiatry 2005; 57:1313-23.

7. Voeller KKS. Attention-deficit hyperactivity disorder (ADHD). I Child Neurol 2004; 19:798-814.

8. Saha $T$, Chatterje M, Sinha S, Rajamma U, Mukhopadhyay K. Components of the folate metabolic pathway and ADHD core traits: an exploration in eastern Indian probands. I Hum Genet 2017; 62:687-95.

9. Bolander-Gouaille C, Bottiglieri T. Homocysteine- Related Vitamins and Neuropsychiatric Disorders. 2007. Paris: Springer.

10. Schlotz W, Jones A, Phillips DI, Gale CR, Robinson SM, Godfrey GM. Lower maternal folate status in early pregnancy is associated with childhood hyperactivity and peer problems in offspring. I Child Psychol Psychiatry 2010; 51:594-602.

11. Gokcen C, Kocak N, Pekgor A. Methylenetetrahydrofolate Reductase Gene Polymorphisms in Children with Attention Deficit Hyperactivity Disorder. Int I Med Sci 2011; 8:523-8.

12. Lakhan SE, Vieira KF. Nutritional therapies for mental disorders. Nutr I 2008; 7:1-8.

13. Seppala J, Koponen $\mathrm{H}$, Kautiainen $\mathrm{H}$, et al. Association between vitamin B12 levels and melancholic depressive symptoms: a Finnish population-based study. BMC Psychiatry 2013; 13:145.

14. Biemans E, Hart HE, Rutten GE, Cuellar Renteria VG, KooijmanBuiting AM, Beulens JW. Cobalamin status and its relation with depression, cognition and neuropathy in patients with type 2 diabetes mellitus using metformin. Acta Diabetol 2015; 52:38393.

15. Moorthy D, Peter I, Scott TM, et al. Status of vitamins B-12 and B-6 but not of folate, homocysteine, and the methylenetetrahydrofolate reductase C677T polymorphism are associated with impaired cognition and depression in adults. Nutr 2012; 142:1554-60.

16. Okereke OI, Cook NR, Albert CM, Van Denburgh M, Buring JE, Manson JE. Effect of long-term supplementation with folic acid and $\mathrm{B}$ vitamins on risk of depression in older women. $\mathrm{Br}$ ) Psychiatry 2015; 206:324-31.

17. Beydoun MA, Shroff MR, Beydoun HA, Zonderman AB. Serum folate, vitamin B-12, and homocysteine and their association with depressive symptoms among U. S. adults. Psychosom Med 2010; 72:862-73.

18. Turgay A. The DSM-IV Based child and adolescent behavior rating scale. Ontario, Integrative Therapy Institute, Canada, 1995 (Unpublished form).

19. Ercan ES, Amado S, Somer O, Çıkoğlu S. Development of a test battery for the assessment of attention deficit hyperactivity disorder. Turk C Child Adolesc Ment Health 2001; 8:132-44.

20. Birmaher B, Khetarpal S, Brent $D$, et al. The screen for child anxiety related emotional disorders (SCARED): Scale construction and psychometric characteristics. I Am Acad Child Adolesc Psychiatry 1997; 36:545-53.

21. Çakmakçı FK. The reliability and validity study of the screen for child anxiety related emotional disorders (SCARED). Unpublished Expertise Thesis, Department of child and adolescent psychiatry, Kocaeli University, Faculty of Medicine, Kocaeli; 2004.

22. Guy W. Clinical global impression scale. The ECDEU assessment manual for psychopharmacology-revised. volume DHEW Publ No ADM 1976; 76:218-22.

23. Reynolds E. Vitamin B12, folic acid, and the nervous system. Lancet Neurol 2006; 5:949-60.

24. Dogan M, Ariyuca S, Peker E, et al. Psychotic disorder, hypertension and seizures associated with vitamin B12 deficiency: a case report. Hum Exp Toxicol 2012; 31:410-3.

25. Dogan M, Ozdemir O, Sal EA, et al. Psychotic disorder and extrapyramidal symptoms associated with vitamin B12 and folate deficiency. J Trop Pediatr 2009; 55:205-7.

26. Serin $H M$, Kara AO, Oğuz B. West syndrome due to vitamin B12 deficiency. Turk Pediatri Ars 2015; 50:251-3.

27. Louwman MW], van Dusseldorp M, vande Vijver FJR, et al. Signs of impaired cognitive function in adolescents with marginal cobalamin status. Am I Clin Nutr 2000; 72:762-9.

28. Strand TA, Taneja S, Ueland PM, et al. Cobalamin and folate status predicts mental development scores in North Indian children12-18 mo of age. Am J Clin Nutr 2013; 97:310-7.

29. vande Rest O, van Hooijdonk LW, Doets E, Schiepers OJ, Eilander A, de Groot LC. B vitamins and n-3 fatty acids for brain development and function: review of human studies. Ann Nutr Metab 2012; 60:272-92.

30. Ssonko M, Ddungu $H$, Musisi S. Low serum vitamin B12 levels among psychiatric patients admitted in Butabika mental hospital in Uganda. BMC Res Notes 2014; 7-90.

31. Imbard A, Benoist JF, Blom H). Neural tube defects, folic acid and metylation. Int J Environ Res Public Health 2013; 10:4352-89.

32. Zhang XM, Huang GW, Tian ZH, Ren DL, Wilson IX. Folate stimulates ERK1/2 phosphorylation and cell proliferation in fetal neural stem cells. Nutr Neurosci 2009; 12:226-32.

33. Gilbody $\mathrm{S}$, Lightfoot $\mathrm{T}$, Sheldon $\mathrm{T}$. Is low folate a risk factor for depression? A metaanalysis and exploration of heterogeneity. I Epidemiol Commun Health 2007; 61:631-7. 
Öztürk et al.

34. Møllehave LT, Skaaby T, Simonsen KS, et al. Association studies of genetic scores of serum vitamin B12 and folate levels with symptoms of depression and anxiety in two danish population studies. Eur J Clin Nutr 2017; 71:1054-60.

35. Bjelland I, Tell GS, Vollset SE, Refsum H, Ueland PM. Folate, vitamin B12, homocysteine, and MTHFR 677->T polymorphism in anxiety and depression: the Hordaland Homocysteine Study. Arch Gen Psychiatry 2003; 60:618-26.
36. Bala KA, Doğan M, Kaba S, Mutluer T, Aslan O, Doğan SZ. Hormone disorder and vitamin deficiency in attention deficit hyperactivity disorder (ADHD) and autism spectrum disorders (ASDs). J Pediatr Endocrinol Metab 2016; 29:1077-82.

37. Gariardic M, Doğan M, Bala KA, et al. Association of Attention Deficit Hyperactivity Disorder and Autism Spectrum Disorders with Mean Platelet Volume and Vitamin D. Med Sci Monit 2017; 23:1378-84. 